\title{
Anatomia da glândula nodal em Moutabea chodatiana Huber e Securidaca bialata Benth. (Polygalaceae) ${ }^{1}$
}

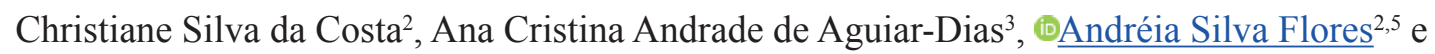 \\ André Olmos Simões ${ }^{4}$
}

Recebido: 6.02.2018; aceito: 8.08.2018

\begin{abstract}
Anatomy of the nodal gland in Moutabea chodatiana Huber and Securidaca bialata Benth. (Polygalaceae)). Despite the common occurrence and taxonomic value of nodal glands in Polygalaceae, little is known about the anatomy and ontogeny of these organs. Therefore, the aim of this study is to analyze the origin and structure of nodal glands in representatives of two genera of Polygalaceae: Securidaca L. and Moutabea Aubl. Samples from the fourth node were taken, fixed and processed for analysis under light and scanning electron microscopy, according to conventional techniques in plant anatomy. Our results show that, regardless their size and shape, glands from all analyzed taxa have a similar stipular origin, being connected to the leaf trace, and confirming previous studies on the foliar nature of these structures in the family. Keywords: Fabales, plant anatomy, Polygalaceae, stipular glands
\end{abstract}

RESUMO - (Anatomia da glândula nodal em Moutabea chodatiana Huber e Securidaca bialata Benth. (Polygalaceae)). Apesar da representatividade e valor taxonômico de glândulas nodais em Polygalaceae, ainda são poucos os estudos que investigam a natureza anatômica destas estruturas. Diante disto, o objetivo deste estudo foi analisar a origem e a estrutura das glândulas nodais em representantes de dois gêneros de Polygalaceae: Securidaca L. e Moutabea Aubl. Amostras de regiões nodais do quarto nó foram coletadas, fixadas e processadas para estudos em microscopia de luz e de varredura, segundo técnicas convencionais em anatomia vegetal. As glândulas dos táxons analisados, apesar de formas distintas, apresentaram a mesma origem, todas ligadas ao traço foliar confirmando estudos anteriores sobre a natureza foliar destas estruturas na família. Palavras-chave: anatomia, Fabales, glândula estipular, Polygalaceae

\section{Introdução}

As estruturas secretoras em Angiospermas apresentam diferentes formas desde idioblastos (células isoladas) a tecidos ou estruturas multicelulares variadas, dentre estas estão as glândulas secretoras (Fahn 1979).

As glândulas estão distribuídas nas folhas, em regiões nodais do caule ou inflorescências em um terço dos gêneros de Polygalaceae Hoffmanns. \& Link pertencentes às tribos Moutabeae Chodat e Polygaleae Chodat (Ericksen \& Persson 2007; Aguiar-Dias et al. 2011). A presença das glândulas nodais em Polygalaceae foi utilizada como um caráter para a definição de alguns gêneros. Estas estruturas foram mencionadas nas investigações que analisam a morfologia e taxonomia dessa família desde os estudos de Chodat (1891), e alguns estudos utilizam a presença e ausência destas estruturas como caracteres taxonômicos (Ludtke et al. 2009, 2013).Todavia, poucos estudos enfatizavam a análise estrutural destas glândulas e sua relação com a história do grupo em questão. Atualmente, é possível observar que as glândulas nodais ocorrem em gêneros basais e derivados na família, possuindo características que auxiliam na delimitação genérica, como por exemplo, em Caamembeca J.F.B. Pastore. A presença de glândulas nodais cônicas é considerada como uma das

1. Parte da Dissertação de Mestrado da primeira Autora

2. Instituto de Amparo à Ciência, Tecnologia e Inovação do Estado de Roraima, Museu Integrado de Roraima, Herbário, Av. Brigadeiro Eduardo Gomes, 1128, 69330-640 Boa Vista, RR, Brasil

3. Universidade Federal do Pará, Instituto de Ciências Biológicas, Av. Perimetral, 2-224, 66075-110 Belém, PA, Brasil

4. Universidade Estadual de Campinas, Instituto de Biologia, Departamento de Biologia Vegetal, Rua Monteiro Lobato, 255, 13083-970 Campinas, SP, Brasil

5. Autor para correspondência: andreiasflores@gmail.com 
principais sinapomorfias morfológicas neste gênero (Pastore et al. 2017).

A natureza destas glândulas foi considerada por alguns estudos como sendo de origem caulinar (Weberling 1974, Eriksen \& Persson 2007, Marques \& Peixoto 2007), entretanto estudos anatômicos em Xanthophyllum Roxb., Caamembeca e Moninna Ruiz \& Paiva vêm mostrando que as glândulas nodais têm sua origem nas extremidades do traço foliar (Dickison 1973, Aguiar-Dias et al. 2011, Filgueira et al. 2016, 2017).

Em Polygalaceae, a estrutura e origem das glândulas nodais foram estudadas principalmente em espécies asiáticas de Xanthophyllum (Dickison 1973) e em poucas espécies de Caamembeca (Aguiar-Dias et al. 2011, Filgueira et al. 2016) e Moninna (Filgueira et al. 2017). Alguns gêneros ainda não foram amostrados em estudos ontogenéticos e estruturais da glândula nodal, dentre estes, estão Moutabea Aubl. (tribo Moutabeae) e Securidaca L. (tribo Polygaleae) que apresentam várias espécies nativas no Brasil. Ambos os gêneros são monofiléticos e distintos pelo número de carpelos, com dois carpelos em Securidaca e 3-8 em Moutabea (Eriksen 1993). Dentre as espécies brasileiras, Moutabea chodatiana Huber é uma espécie amazônica cujos frutos drupáceos são comestíveis por apresentar polpa adocicada (Cavalcante 2010). Securidaca bialata Benth. é uma liana com frutos alados encontrada no Brasil principalmente nas regiões norte, nordeste e centro-oeste (Marques 1996). Estas espécies apresentam potencial econômico devido ao fruto comestível (M. chodatiana) e são facilmente encontradas na Região Amazônica.

Este estudo tem como objetivo investigar a origem das glândulas nodais em representantes de dois gêneros de ocorrência brasileira, Moutabea e Securidaca, visando ampliar os estudos sobre a estrutura interna das glândulas nodais em Polygalaceae.

\section{Material e métodos}

Para este estudo foram utilizados materiais previamente coletados em áreas de margem de igapó na FLONA Caxiuanã, Estado do Pará e depositados no Herbário do Museu Integrado de Roraima (MIRR) sob os números MIRR 9386 (M. chodatiana) e MIRR 9385 (S. bialata).

Para as análises em microscopia de luz, as amostras da região nodal do quarto nó visível das espécies selecionadas foram fixadas em FAA(Johansen 1940) por 24 horas, mantidas em vácuo para retirada do ar contido nos espaços intercelulares e, em seguida, estocadas em etanol $70 \%$. As amostras da região nodal foram submetidas ao processo de inclusão em resina sintética (2 -hidroxi-etil)-metacrilato Leica ${ }^{\circledR}$ e seccionados em micrótomo rotativo nos planos transversais e longitudinais $(10-15 \mu \mathrm{m})$ e corados em azul de toluidina (Johansen 1940). Determinados cortes foram submetidos à luz polarizada a fim de verificar a ocorrência de lignificação. As lâminas histológicas foram montadas com resina sintética Entellan ${ }^{\circledR}$. As fotomicrografias foram realizadas em vários aumentos com auxílio de câmera Canon Powershot A660IS acoplada ao microscópio Zeiss Axiostar plus (Laboratório de Aracnídeos - MPEG).

Para as análises de Microscopia Eletrônica de Varredura (MEV) as amostras de regiões nodais foram fixadas em FAA por 24 h e desidratadas em série etanólica crescente (Johansen 1940). Em seguida, foram processadas em secador de ponto crítico, montadas em suportes metálicos e metalizadas com ouro. As observações e captura de imagens foram feitas em microscópio eletrônico LEO modelo 1450 VP, do Laboratório Institucional de Microscopia Eletrônica de Varredura do Museu Paraense Emílio Goeldi.

\section{Resultados e Discussão}

As glândulas nodais de Polygalaceae foram descritas como sésseis, subsésseis, curto-estipitadas e estipitadas, com formas variadas, desde discóides, crateriformes, circulares, pateliformes a cilíndricas (Ericksen (1993), Lüdtke et al. (2008)). No presente estudo, foram adotados os termos plana e elevadas para descrever as glândulas, como utilizado para as formas dos nectários extraflorais em Díaz-Castellazo et al. (2005), Machado et al. (2008) e Melo et al. (2010), em diferentes famílias. Morfologicamente, as glândulas apresentaram forma orbicular e plana com 0,6-0,7 mm de diâmetro em Moutabea chodatiana e em Securidaca bialata as glândulas são umbonadas e elevadas em relação ao tecido epidérmico com 0,5-0,8 $\times 0,4-1,1 \mathrm{~mm}$ diâmetro (figura $1 \mathrm{a}-\mathrm{d}$ ). Tricomas tectores foram observados somente próximos à glândula.

Estruturalmente em corte transversal, a epiderme das duas espécies analisadas se mostrou unisseriada com fina cutícula e estômatos ausentes. A região apical das glândulas de S. bialata apresentou epiderme em paliçada que delimita um orifício que se prolonga sob a forma de um canal central (figura 3d) enquanto que 


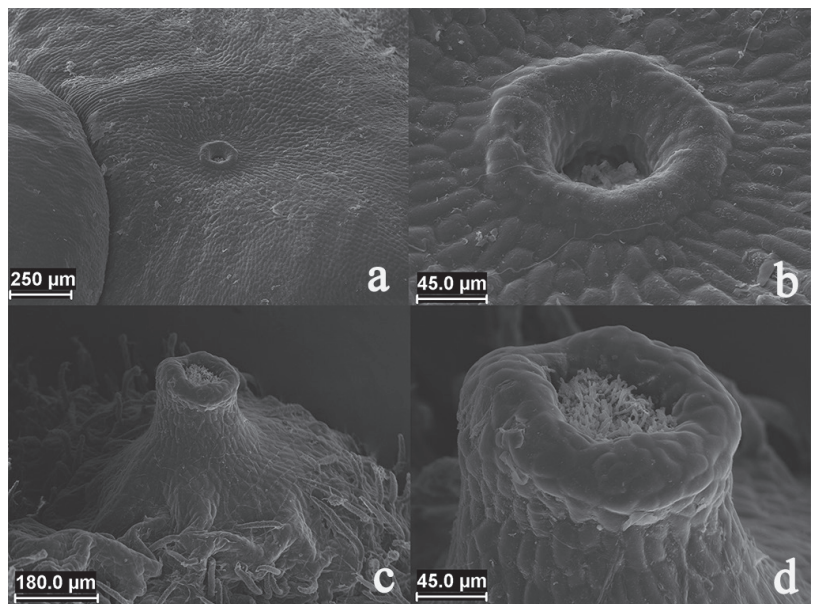

Figura 1. Microscopia eletrônica de varredura das glândulas nodais. a-b Moutabea chodatiana Huber. a. glândula plana, orbicular. b. abertura da glândula. c-d Securidaca bialata Benth. c. glândula elevada, umbonada. d. abertura da glândula.

Figure 1. Scanning electron microscopy of the nodal glands: a-b Moutabea chodatiana Huber. a. flat gland, orbicular. b. gland aperture. c-d. Securidaca bialata Benth. c. elevated gland, umbonate. d. gland aperture.

M. chodatiana apresentou a abertura da glândula no mesmo nível da epiderme (figuras 2a,b). As paredes periclinais e anticlinais das células epidérmicas se mostraram espessadas (figura 3d). Nas regiões mediana e basal das glândulas, a cutícula foi observada apenas na parede periclinal externa das células epidérmicas.

Securidaca bialata apresentou os tecidos parenquimáticos e secretores parcialmente inseridos na região cortical do caule, ficando apenas uma proeminência para o meio externo com o canal apical por onde a secreção é liberada (figura 3 a,b). Moutabea chodatiana apresentou o tecido parenquimático e secretor das glândulas totalmente inserido na região cortical do caule (figuras $2 \mathrm{a}, \mathrm{b}$ ). Em ambas as espécies também foram observadas esclereides em torno das glândulas (figuras 2 d, 3 e).

A morfologia e localização dos tecidos secretores parecem mostrar um padrão nas tribos em Polygalaceae. Em espécies de Xantophyllum os tecidos secretores se mostraram inseridos totalmente na região cortical sem a presença de projeção parenquimática para a liberação do exsudato (Dickison 1973). Por outro lado, Monnina exalata A.W. Benn., Caamembeca spectabilis (DC.) J.F.B. Pastore e C. laureola (A. St.-Hil. \& Moq.) J.F.B. Pastore apresentaram uma projeção parenquimática que forma um orifício externo. O tecido secretor pode se encontrar parcialmente inserido no córtex em Monnina exalata e Caamembeca spectabilis ou

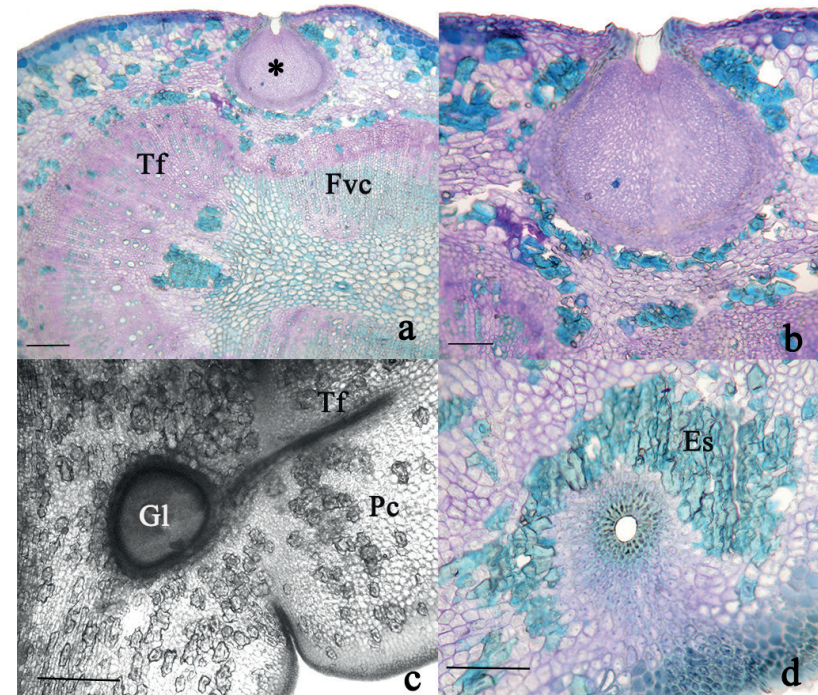

Figura 2. Moutabea chodatiana Huber. a. Vista geral da região nodal. Tecido secretor da glândula $(*)$, traço foliar (Tf) e feixe vascular do caule (Fvc). b. Detalhe da abertura da glândula. c. Glândula (Gl) ligada ao traço foliar (TF) (Pc- pecíolo). d. Corte transversal da glândula envolta por esclereídes (Es). Escalas: a = $40 \mu \mathrm{m} ; \mathrm{b}, \mathrm{c}, \mathrm{d}=25 \mu \mathrm{m}$.

Figure 2. Moutabea chodatiana Huber. a. Overview of the nodal region. Gland secretory tissue $(*)$, leaf trace (Tf) and vascular stem bundle (Fvc). b. Detail of gland aperture. c. Gland (Gl) attached to leaf trace (Tf) (Pc-petiole). d. Cross section of the gland surrounded by sclereids (Es). Scales: $a=40 \mu \mathrm{m} ; \mathrm{b}, \mathrm{c}, \mathrm{d}=25 \mu \mathrm{m}$.

localizado exclusivamente na projeção do orifício glandular em C. laureola (Aguiar et al. 2011, Filgueira et al. 2016, Filgueira et al. 2017). Desta forma, os gêneros pertencentes às tribos mais basais de Polygalaceae, Moutoubeae e Xanthophylleae parecem apresentar um padrão morfológico nos quais as glândulas apresentaram os tecidos secretores inseridos totalmente na região cortical e projeção parenquimática reduzida ou ausente, enquanto que em Polygaleaea os tecidos secretores se mostraram inseridos parcialmente na região cortical ou na projeção parenquimática que forma o orifício glandular.

As glândulas são vascularizadas por um único feixe, situado em posição central (figuras 2 c, 3 b). Na base das glândulas, o feixe é anficrival e nas demais partes são constituídas apenas por floema que envolve as células secretoras (figura $3 \mathrm{c}$ ). Todas as glândulas analisadas possuem sua vascularização ligada ao traço foliar (figuras 2 a,c, 3 a,b), evidenciando assim, uma origem foliar e não caulinar. Deste modo, as glândulas nodais podem ser consideradas como estípulas modificadas como mencionado pela primeira vez para 


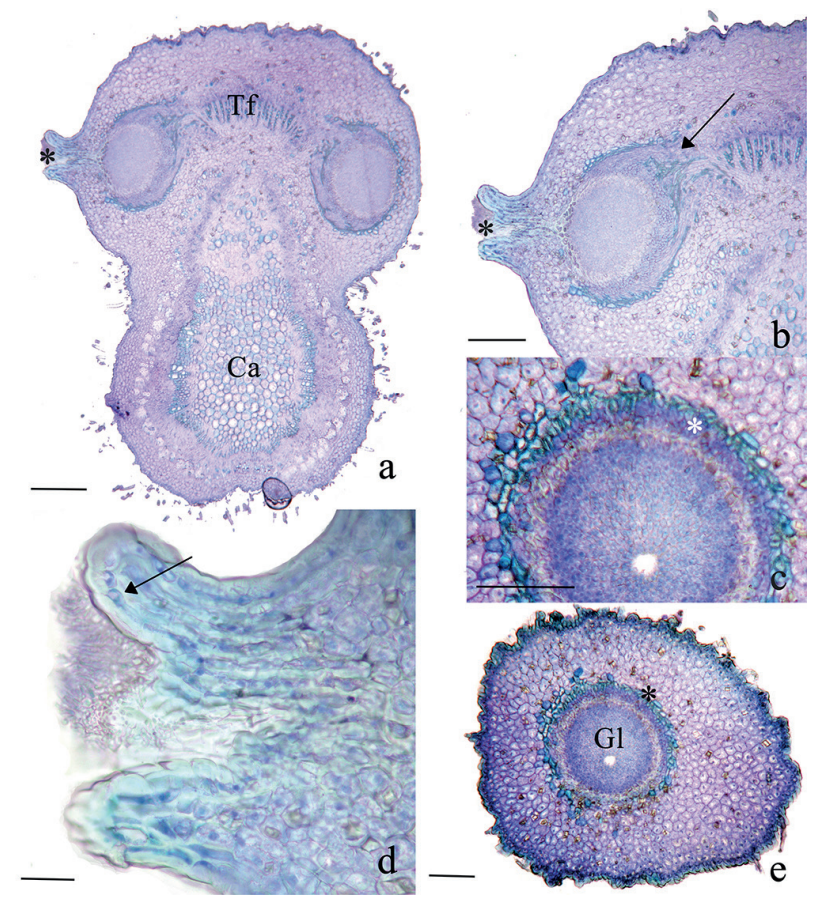

Figura 3. Securidaca bialata Benth. a. Vista geral da região nodal (Ca: caule) com traço foliar (Tf) e canal apical (*), b. Detalhe da glândula e sua ligação ao traço foliar (seta) e abertura do canal apical $(*)$, c. Detalhe da glândula nodal em corte transversal indicando o floema $\left({ }^{*}\right)$, d. Detalhe da abertura da glândula com espessamento das paredes celulares da epiderme (seta), e. Corte transversal da glândula $(\mathrm{Gl})$ envolta por esclereides $(*)$. Escalas: $\mathrm{a}=40 \mu \mathrm{m} ; \mathrm{b}=30 \mu \mathrm{m} ; \mathrm{c}=25 \mu \mathrm{m} ; \mathrm{d}=15 \mu \mathrm{m} ; \mathrm{e}=30 \mu \mathrm{m}$.

Figure 3. Securidaca bialata Benth. a Overview of the nodal region (Ca: stem) with leaf trace (Tf) and apical channel (*), b. Detail of gland and its connection to the leaf trace (arrow) and apical channel $\left.{ }^{*}\right)$, c. Detail of nodal gland in cross section showing phloem $(*)$, d. Detail of gland aperture with a thickening of epidermal epiderm cell walls (arrow), e. Cross section of the gland (Gl) surrounded by sclereids $(*)$. Scales: $a=40 \mu \mathrm{m} ; \mathrm{b}=30 \mu \mathrm{m} ; \mathrm{c}=25 \mu \mathrm{m} ; \mathrm{d}=$ $15 \mu \mathrm{m} ; \mathrm{e}=30 \mu \mathrm{m}$.

a família por Aguiar et al. (2011) em Polygala laureola A. St.-Hil. \& Moq.

Os estudos sobre a estrutura interna e ontogenia destas glândulas em representantes de Polygalaceae vêm confirmando que as glândulas nodais na família apresentam vascularização ligada ao traço foliar. Isto foi indicado primeiramente por Dickinson (1973) em espécies de Xanthophyllum ressaltando a necessidade de ampliação de estudos para uma melhor compreensão sobre estas estruturas que considerou como glândulas estipulares.

Até o trabalho de Aguiar-Dias et al. (2011), não existiam registros de estípulas na família em questão. As glândulas nodais foram consideradas como nectários estipulares devido, não somente pela sua morfologia, mas pela produção de néctar em espécies de Caamembeca e Moninna (Aguiar et al. 2011, Filgueiras et al 2016, 2017). Devido a pequena quantidade de exsudato produzido não foi possível elucidar a natureza do material secretado durante este estudo, mas estruturalmente as glândulas apresentam similaridades na composição dos tecidos com as espécies já testadas em relação a presença de néctar.

Os resultados obtidos neste trabalho ampliaram o conhecimento sobre a estrutura interna das glândulas nodais em Polygalaceae, confirmando estudos anteriores sobre a natureza foliar destas estruturas secretoras. Ainda resta testar a natureza do exsudato produzido para verificar se estas glândulas também podem ser consideradas secretoras de néctar como nos demais representantes da família.

\section{Agradecimentos}

Os autores agradecem ao Programa de Programa de Pós graduação em Ciências Biológicas - Botânica Tropical; ao CNPq pela bolsa de mestrado concedida a CSC.

\section{Literatura citada}

Aguiar-Dias, A.C.A., Yamamoto, K. \& Castro, M.M. 2011. Stipular extranuptial nectaries new to Polygala: morphology and ontogeny. Botanical Journal of the Linnean Society 166: 40-50.

Cavalcante, P. 2010. Frutas comestíveis na Amazônia. 7.ed. Museu Paraense Emílio Goeldi, Belém.

Chodat, R. 1891. Monografia Polygalacearum. Mémories de la Soviété de Physique et d'Histoire Naturelle de Genève 31: 1-500.

Díaz-Castelazo, C., Rico-Gray, V., Ortega, F. \& Ángeles, G. 2005. Morphological and Secretory Characterization of Extrafloral Nectaries in Plants of Coastal Veracruz, Mexico. Annals of Botany 96: 1175-1189.

Dickison, W.C. 1973. Nodal and leaf anatomy of Xanthophyllum (Polygalaceae). Botanical Journal of the Linnean Society 67: 103-115.

Eriksen, B. 1993. Phylogeny of the Polygalaceae and its taxonomic implications. Plant Systematics and Evolution 186: 33-55.

Eriksen, B. \& Persson, C. 2007. Polygalaceae. In: K. Kubitzki (ed.). The families and genera of vascular plants. Springer, Verlag, Berlin, v. 9, pp. 345-363.

Fahn, A. 1979. Secretory Tissues in Plants. Academic Press, London, New York, San Franscisco.

Kikuchi, T.Y.S. \& Coelho-Ferreira, M.R. 2016. Morphology, ontogeny and structure of the stipular nectaries in Caamembeca spectabilis (Polygalaceae). Acta Amazonica 46: 127-132. 
Filgueira, J.P.P.S., Pastore, J.F.B., Demarco, D., AguiarDias, A.C.A. 2017. Nectários estipulares em Monnina exalata A.W. Benn (Polygalaceae). Biota Amazônia 7: 1-3.

Johansen, D.A. 1940. Plant microtechnique. McGraw Book, New York.

Lüdtke, R., Souza-Chies, T.T. \& Miotto, S.T.S. 2008. Flora ilustrada do Rio Grande do Sul: Bredemeyera Willd. e Securidaca L. (Polygalaceae) na Região Sul do Brasil. Revista Brasileira de Biociências 6: 69-79.

Lüdtke, R., Souza-Chies, T.T. \& Miotto, S.T.S. 2009. O gênero Monnina (Polygalaceae) na Região Sul do Brasil. Acta Botânica Brasílica 23: 175-195.

Lüdtke, R., Souza-Chies, T.T. \& Miotto, S.T.S. 2013. $\mathrm{O}$ gênero Polygala L. (Polygalaceae) na região Sul do Brasil. Hoehnea, 40: 1-50.

Machado, S.R., Morellato, L.P.C., Sajo, M.G. \& Oliveira, P.S. 2008. Morphological patterns of extrafloral nectaries in woody plant species of the Brazilian Cerrado. Plant Biology 10: 660-673.
Marques, M.C.M. 1996. Securidaca L. (Polygalaceae) do Brasil. Arquivos do Jardim Botânico do Rio de Janeiro 34: 7-144.

Marques, M.C.M. \& Peixoto, A.L. 2007. Estudo taxonômico de Polygala subgênero Ligustrina (Chodat) Paiva (Polygalaceae). Rodriguésia 58: 95-146.

Machado, S.R., Morellato, L.P.C., Sajo, M.G. \& Oliveira, P.S. 2008. Morphological patterns of extrafloral nectaries in woody plant species of the Brazilian Cerrado. Plant Biology 10: 660-673.

Melo, Y., Córdula, E., Machado, S.R. \& Alves, M. 2010. Morfologia de nectários em Leguminosae senso lato em áreas de caatinga no Brasil. Acta Botânica Brasílica 24: 1034-1945.

Pastore, J.F.B., Abbott, J.R., Neubig, K.M., Whitten, W.M., Mascarenhas R.B., Mota, M.C.A. \& va den Berg, C. 2017. A molecular phylogeny and taxonomic notes in Caamembeca (Polygalaceae). Systematic Botany 42: 54-62.

Weberling F. 1974. Weitere Untersuchungen zur Morphologie des Unterblattes bei den Dikotylen. Beiträge zur Biologie der Pflanzen 50: 277-289. 